\title{
REFLEXÕES SOBRE O PROCESSO DE APRENDIZAGEM PARA O SÉCULO XXI: UM RELATO DE EXPERIÊNCIA A PARTIR DAS AULAS DE ESTATÍSTICA DE UM CURSO TÉCNICO EM SEGURANÇA DO TRABALHO
}

\author{
REFLECTIONS ON THE LEARNING PROCESS FOR THE 21 ${ }^{\text {ST }}$ CENTURY: \\ A REPORT OF EXPERIENCE FROM THE STATISTICAL CLASSES OF A \\ VOCATIONAL COURSE ON WORK SAFETY
}

\author{
Juliana Campos Sabino de SOUZA ${ }^{1}$ \\ Mateus Gianni FONSECA ${ }^{2}$
}

RESUMO: O presente relato de experiência busca apresentar dois encontros presenciais do componente curricular de Estatística do curso Técnico em Segurança do Trabalho do Campus Ceilândia, do Instituto Federal de Brasília. As atividades desenvolvidas nesses encontros buscaram focar no aprendizado centrado no aluno, em que os mesmos protagonizaram seu processo de aprendizado, na medida que se buscou estimulá-los a desenvolverem pensamento crítico em relação a dados estatísticos referentes à área de segurança do trabalho. Primou-se que as atividades propostas fossem baseadas em dados estatísticos reais, buscando um conhecimento mais aprofundado do cenário da área específica de formação dos alunos. Os mesmos foram divididos em grupos, buscando um trabalho colaborativo e interação entre os pares, de acordo com o que se espera de uma educação voltada ao século XXI. Utilizou-se também Tecnologias da Informação e Comunicação (TIC) para mediar o desenvolvimento de algumas atividades, principalmente na elaboração de tabelas e gráficos. Por resultados, pôde-se perceber que a maior parte dos alunos se sentiram mais motivados em trabalhar numa perspectiva mais ativa, construindo conceitos significativos.

PALAVRAS CHAVE: Aprendizado centrado no aluno. Aprendizado colaborativo. Aprendizagem para o século XXI.

ABSTRACT. This teaching experience report intends to present two assemblies with students of Statistics, a curricular component from the Vocational Course in Work Safety of Ceilândia Campus of the Federal Institute of Brasilia. The activities developed aimed at focusing on student-centered learning, as it was intended to encourage students to develop critical thinking regarding statistical data concerning the area of work safety. The proposed activities were based on authentic statistical data, aiming at developing deeper knowledge of this specific area of the course. Students were organized in groups for a collaborative work and interaction between peers according to what is expected of an education focused on the $21^{\text {st }}$ Century. Some Information and Communication Technologies were also used to mediate some activities, mainly in the elaboration of tables

${ }^{1}$ Instituto Federal de Educação, Ciência e Tecnologia de Brasília (IFB), Brasília - DF - Brasil. E-mail: juliana.souza@ifb.edu.br

2 Instituto Federal de Educação, Ciência e Tecnologia de Brasília (IFB), Brasília - Brasil. E-mail: mateus.fonseca@ifb.edu.br 
and graphs. It turned out that most students felt more motivated to study in a more active perspective.

KEYWORDS: Student-centered learning. Collaborative learning. Critical Thinking.

\section{Introdução}

Trata-se de relato de experiência referente às atividades desenvolvidas junto a duas turmas do curso técnico subsequente ao ensino médio em segurança do trabalho do IFB, Campus Ceilândia, no segundo semestre de 2016, no componente curricular de estatística, na modalidade de educação a distância. O plano do curso em comento prevê 40 horas para o estudo de estatística, embora apenas 8 horas sejam realizadas de maneira presencial, o que é dividido em dois encontros com 4 horas cada.

Visando estimular a construção de conceitos com maior significação por parte dos estudantes nos encontros presenciais, buscou-se propor um trabalho ancorado em metodologias ativas, como o aprendizado centrado no aluno, a partir dos princípios elencados para uma educação para o século XXI que visa, sobretudo, preparar cidadãos para o trato com diferentes problemas de forma autônoma, crítica, criativa, dentre outros (P21, 2016; Newton, Newton, 2014).

As atividades realizadas a distância também serviram para estimular o trabalho autônomo dos estudantes. No entanto, optou-se neste relato por descrever com maiores detalhes apenas os encontros presenciais.

\section{$1^{\circ}$ Encontro presencial}

A atividade a distância desenvolvida na $1^{\circ}$ semana era relacionada ao conhecimento de conceitos básicos relacionados à estatística, como média aritmética, mediana moda, variância e desvio padrão. Visando dar continuidade à atividade postada anteriormente no ambiente virtual, trabalhou-se no primeiro encontro presencial com os alunos a partir do conceito de sala de aula invertida, de modo que tais conceitos pudessem ser consolidados de maneira significativa por cada discente. A turma foi dividida em grupos de 5 participantes. Optou-se por trabalhar em grupos para estimular a comunicação e colaboração entre os pares, a partir da troca de experiências e conhecimentos prévios, sendo essa uma das habilidades para o século 21 (P21, 2016). 
A atividade proposta consistia em cada grupo registrar brevemente no Padlet, que é um aplicativo de internet que possibilita que várias pessoas registrem ideias ao mesmo tempo a partir de textos curtos, o entendimento construído pelo grupo sobre alguns conceitos (moda, mediana, média e desvio padrão), buscando que eles debatessem sobre esses, utilizando seus conhecimentos prévios e as pesquisas realizadas no laboratório de informática.

Após esse registro foi projetado as respostas para que a turma pudesse debater em conjunto sobre as considerações postadas pelos grupos. Embora fosse possível facilmente perceber que a maior parte dos grupos havia copiado os conceitos de sites da internet, a experiência foi importante para suscitar a reflexão de todos, a partir das dificuldades que eles mesmos apresentaram ao serem questionados sobre o que eles entendiam sobre aquele conceito que haviam escrito ou mesmo sobre suas aplicações. Alguns sequer conseguiram demonstrar uma compreensão e inferir informações sobre o que havia registrado, limitando-se a apenas repetir o que estava escrito. Ao se perceber isso foi realizado um momento para que os alunos pudessem pensar sobre o que haviam escrito e dar significado aqueles conceitos que haviam registrado a partir do debate com o grande grupo.

Esse fato pode estar associado à questão dos alunos geralmente não serem estimulados a pensar no significado de conceitos matemáticos, bem como de que maneira esses conceitos podem auxiliar no tratamento de informações em diferentes áreas, mas sim de repetir as informações que são fornecidas, o que se reflete em um hábito passivo, que não contribui para um trabalho ativo na construção e compreensão dos mesmos.

No segundo momento desse encontro foi solicitado que cada grupo elaborasse uma tabela de uma região do Brasil com alguns dados do Anuário Estatístico da Previdência Social (AEPS 2014) relacionados ao quantitativo de acidentes do trabalho do ano de 2014. Além da tabela, cada grupo deveria determinar o valor da moda, mediana e média dos acidentes de trabalho e realizar algumas conclusões com relação a esses dados, analisando o que esses números significavam. Após esse momento cada grupo elaborou um pequeno texto a partir de suas análises e considerações em relação aquela região. Optou-se por trabalhar alguns dados do AEPS 2014 pelo fato de se buscar aproximar os alunos de informações estatísticas relevantes para a sua área de formação, analisando informações reais e não situações hipotéticas, buscando ter um conhecimento mais aprofundado dos dados estatísticos da realidade brasileira, como quantitativo de acidentes em diversas regiões, idade, sexo, tipos de acidentes mais comuns, dentre outros fatores, bem como 
estimulando que os mesmos pudessem perceber sentido em cada variável que manipulavam.

Após essa atividade os grupos compartilharam brevemente os dados obtidos e considerações referentes à região a qual analisaram. E é nesse momento que se destaca a nobreza da metodologia, pois os alunos puderam comparar a quantidade de acidente nas diversas regiões do país, conjecturar hipóteses das razões de maior recorrência de acidentes em um lugar em relação a outro, dentre outras considerações, demonstrando, de fato, os conhecimentos construídos a partir da interação proposta.

\section{$2^{\circ}$ encontro presencial}

No primeiro momento desse encontro foi realizado um feedback dos gráficos que foram enviados pelos alunos, referente a uma atividade realizada a distância. A importância do feedback já foi destacada por diversos autores, como Fernandes (2009) e Brookhart (2008), pelo fato de possibilitar ao estudante perceber seus equívocos e conhecer novos caminhos de resolução. Nessa ótica, realizou-se um feedback individual pelo Moodle e um feedback coletivo em sala de aula, destacando os erros mais recorrentes e algumas considerações sobre as resoluções apresentadas.

Nesse encontro também foi trabalhado o tema de porcentagem. Para tanto foram selecionadas duas reportagens relacionadas ao tema de acidentes de trabalho para realizar uma problematização inicial. Os alunos formaram grupos de 4 pessoas e cada grupo recebeu um estudo dirigido baseado em uma reportagem jornalística para que pudessem analisar alguns dados com relação às porcentagens apresentadas. As perguntas elaboradas para o estudo dirigido buscavam instigar os alunos a refletir sobre as porcentagens apresentadas, e não apenas realizar cálculos algorítmicos, estimulando-os a pensar sobre esses dados, como por exemplo, "Podemos comparar a porcentagem de aumento, ou diminuição, do quantitativo de acidentes de dois lugares diferentes?" e "Quais as variáveis que estão envolvidas quando se trabalha com porcentagem?”. Também foi solicitado que eles elaborassem um gráfico de um dos dados, não sendo esse previamente definido, de maneira que cada grupo detinha autonomia para escolher os dados que consideraram mais relevantes e o tipo de gráfico a ser utilizado.

Optou-se por utilizar recursos computacionais para a construção dos gráficos tendo em vista a importância da utilização de Tecnologias de Informação e Comunicação (TICs) 
para o processo educacional, destacado por diversos autores (FIORENTINI; LORENZATO, 2006; MIRANDA 2007). Os alunos deveriam justificar o motivo de ter escolhido aquele tipo de gráfico para apresentar os dados, bem como foi questionado se eles poderiam utilizar outro tipo de gráfico que também fornecesse uma adequada representação gráfica dos mesmos. Essa estratégia estimulou os alunos a refletir sobre a forma como os dados eram apresentados, com vistas a estimular o pensamento crítico dos mesmos.

\section{Considerações sobre as atividades}

Os alunos relataram ter considerado as atividades interessantes pelo fato de terem sido mais dinâmicas e atrativas do que as aulas expositivas de matemática que estão habituados.

Vale registrar que os alunos brasileiros parecem deter certa dificuldade quando estimulados a um trabalho ativo de aprendizagem, sendo que algumas vezes podia-se notar que eles finalizavam as atividades mais rapidamente, sem por vezes valorizar o tempo destinado ao debate para a construção de seu conhecimento. De fato, mais atividades como essas devem ser realizadas até para que os estudantes concebam a cultura de serem responsáveis pela criação de conceitos significativos para si e estimulá-lo a se perceber como centro do processo do seu aprendizado.

Acredita-se que valorizar os momentos de aula para estimular o trabalho coletivo, a pesquisa, comunicação, pensamento crítico, dentre outros, é de muito valor quando se espera fomentar uma educação que responda aos anseios do presente século, seja em decorrência de formar cidadãos com conhecimento sólido em determinadas áreas, seja pela possibilidade de contribuir para que se tornem cidadãos aptos a, com autonomia, buscarem soluções para diferentes situações imprevisíveis.

\section{REFERÊNCIAS}

BROOKHART, S. M. How to give effective feedback to your students. Alexandria: Association for Supervision and Curriculum Development, 2008.

FERNANDES, D. Avaliar para aprender: fundamentos, práticas e políticas. São Paulo: Editora Unesp, 2009. 
FIORENTINI, D.; LORENZATO, S. Investigação em educação matemática: percursos teóricos e metodológicos. $1^{\text {a }}$ Ed. Campinas: Autores Associados, 2006.

MIRANDA, G. L. Limites e possibilidades das TIC na educação. Revista de Ciências da Educação, n. 03, p. 41-50, 2007.

NEWTON, L. D.; NEWTON, D. P. Creativity in 21 st century education. Prospects, 2014.

P21 - Partnership for 21 st Century Learning. Framework for 21st Century

Learning, 2016. Disponível em:

<http://www.p21.org/storage/documents/docs/P21_framework_0816.pdf>. Acesso em: 8 maio 2017.

\section{Como referenciar este relato de experiência:}

SOUZA, Juliana Campos Sabino de;; FONSECA, Mateus Gianni. Reflexões sobre o processo de aprendizagem para o século XXI: um relato de experiência a partir das aulas de Estatística de um curso técnico em Segurança do Trabalho. Revista Ibero-Americana de Estudos em Educação, Araraquara, v. 13, n. esp1, p. 564-569, maio 2018. E-ISSN: 1982-5587. DOI: 10.21723/riaee.nesp1.v13.2018.11455

Submetido em: $30 / 10 / 2017$

Aprovado em: 01/01/2018 